\title{
Effects of osteopontin inhibition on radiosensitivityof MDA-MB-231 breast cancer cells
}

\author{
Antje Hahnel ${ }^{1 *}$, Henri Wichmann ${ }^{1}$, Matthias Kappler ${ }^{1}$, Matthias Kotzsch $^{3}$, Dirk Vordermark ${ }^{1}$, Helge Taubert ${ }^{2}$, \\ Matthias Bache
}

\begin{abstract}
Background: Osteopontin (OPN) is a secreted glycophosphoprotein that is overexpressed in various tumors, and high levels of OPN have been associated with poor prognosis of cancer patients. In patients with head and neck cancer, high OPN plasma levels have been associated with poor prognosis following radiotherapy. Since little is known about the relationship between OPN expression and radiosensitivity, we investigated the cellular and radiation induced effects of OPN siRNA in human MDA-MB-231 breast cancer cells.
\end{abstract}

Methods: MDA-MB-231 cells were transfected with OPN-specific siRNAs and irradiated after $24 \mathrm{~h}$. To verify the OPN knockdown, we measured the OPN mRNA and protein levels using qRT-PCR and Western blot analysis.

Furthermore, the functional effects of OPN siRNAs were studied by assays to assess clonogenic survival, migration and induction of apoptosis.

Results: Treatment of MDA-MB-231 cells with OPN siRNAs resulted in an 80\% decrease in the OPN mRNA level and in a decrease in extracellular OPN protein level. Transfection reduced clonogenic survival to $42 \%(p=0.008)$, decreased the migration rate to $60 \%(p=0.15)$ and increased apoptosis from $0.3 \%$ to $1.7 \%(p=0.04)$. Combination of OPN siRNA and irradiation at 2 Gy resulted in a further reduction of clonogenic survival to $27 \%(p<0.001)$, decreased the migration rate to $40 \%(p=0.03)$ and increased apoptosis to $4 \%(p<0.005)$. Furthermore, OPN knockdown caused a weak radiosensitization with an enhancement factor of 1.5 at $6 \mathrm{~Gy}(p=0.09)$ and a dose modifying factor $\left(\mathrm{DMF}_{10}\right)$ of 1.1 .

Conclusion: Our results suggest that an OPN knockdown improves radiobiological effects in MDA-MB-231 cells. Therefore, OPN seems to be an attractive target to improve the effectiveness of radiotherapy.

\section{Background}

OPN is a secreted phosphoglycoprotein (SSP1) expressed by osteoclasts and osteoblasts, epithelial cells, activated immune cells and tumor cells. OPN is a member of the SIBLING (Small integrin-binding ligand N-linked glycoproteins) protein family and contains a characteristic RGD-motif that mediates the binding to $\alpha_{v} \beta$-integrin receptors and a thrombin cleavage side, which releases a CD44-binding domain. Several signaling cascades such as the NF-kB/IkB $\alpha / \mathrm{IKK}$ pathway, PI3'-kinase/Akt pathway and the MAPK-dependent pathway are activated by the interaction between OPN and membrane receptors and take part in a variety of normal and pathologic processes.

\footnotetext{
* Correspondence: antje.hahnel@medizin.uni-halle.de

'Department of Radiotherapy, Martin-Luther-University Halle-Wittenberg,

Dryanderstr.4, 06110 Halle, Germany

Full list of author information is available at the end of the article
}

Therefore, the OPN protein influences processes that are important for tumor progression and metastasis (e.g., proliferation, cell motility, migration, invasion and apoptosis; reviewed in [1,2]).

In various studies, OPN overexpression has been linked to high invasive and metastatic potential, recurrent disease and poor prognosis for cancer patients [3-6]. Moreover, a recent immunohistochemical study of prostate cancer tissues demonstrated that OPN protein expression is not increased after radiotherapy. However, patients with aggressive prostate cancer had significantly higher OPN protein expression, which was associated with decreased freedom from biochemical failure [7]. Furthermore, a study of rectal cancer showed that patients who received successful therapy had much lower pre-therapy OPN levels compared to patients who later developed metastases [8]. OPN has been discussed
C Biomed Central

C 2010 Hahnel et al; licensee BioMed Central Ltd. This is an Open Access article distributed under the terms of the Creative Commons Attribution License (http://creativecommons.org/licenses/by/2.0), which permits unrestricted use, distribution, and reproduction in any medium, provided the original work is properly cited. 
not only as tumor marker but also as a marker of hypoxia $[9,10]$. In a previous report from our group, immunohistochemical OPN expression was found to be associated with low tumor oxygenation in advanced head and neck cancer treated with radiotherapy or chemoradiation [11]. Similarly, Le and co-workers reported that high OPN plasma levels are associated with tumor hypoxia in head and neck squamous cell carcinomas and correlate with poor clinical outcome [12]. In addition, a clinical study by Overgaard and co-workers [13] found that high OPN plasma concentrations are associated with a poor prognosis after radiotherapy for patients with head and neck cancer. However, prognosis of patients with high OPN plasma levels could be improved after treatment with the hypoxic radiosensitizer nimorazole [13]. It is known that tumor hypoxia is a major determinant of radioresistance. However, little is known regarding the relationship between OPN expression levels in tumor cells and their radiosensitivity. Therefore, it is important to investigate OPN and its role in cancer progression to improve the opportunities of cancer therapy, especially the effectiveness of radiotherapy.

It is well known that OPN plays an important role in breast cancer. Several studies prove that OPN is overexpressed in breast cancer and that this correlates with high malignancy, poor prognosis and survival $[3-5,14,15]$. Accordingly, we chose the MDA-MB-231 cell line to investigate the effect of an OPN knockdown and irradiation on migration, apoptosis and clonogenic survival. Primary tests showed that the MDA-MB-231 cell line is a radiation insensitive cell line (dose response curve is not shown). We determined an $\mathrm{SF}_{2}$-value of 0.60. Other groups described similar $\mathrm{SF}_{2}$-values with an average of $0.65\left(\mathrm{SF}_{2}=0.82\right.$ [16]; $\mathrm{SF}_{2}=0.63$ [17]; $\mathrm{SF}_{2}=0.5$ [18]).

To determine the influence of OPN on migration, apoptosis, clonogenic survival and radiosensitivity, we reduced the OPN mRNA level in MDA-MB-231 breast cancer cells by transfection with OPN specific siRNA.

\section{Methods}

\section{Cell culture conditions}

The human breast cancer cell line MDA-MB-231 was grown as a monolayer in RPMI 1640 containing $25 \mathrm{mM}$
HEPES and L-glutamine (Lonza, Walkersville, USA). The medium was supplemented with $10 \%$ fetal calf serum (FCS) (PAA, Cölbe, Germany), 1\% pyruvate (Invitrogen, Karlsruhe, Germany), 185 units/ml penicillin (Invitrogen), and $185 \mu \mathrm{g} / \mathrm{ml}$ streptomycin (Invitrogen), and cells were cultured in a humidified atmosphere of $3 \% \mathrm{CO}_{2}$ at $37^{\circ} \mathrm{C}$. All experiments were performed with cells in logarithmic growth phase.

\section{Treatment with OPN siRNAs and irradiation}

Two double-stranded OPN siRNA oligonucleotides (Mix, OpnS) and a nonsense siRNA (negative control) were transfected using INTERFERin ${ }^{\text {Tw }}$ reagent as recommended by the manufacturer (Polyplus Transfection Illkirch, France). The cells $\left(4-5 * 10^{5}\right.$ cells) were plated overnight at $37^{\circ} \mathrm{C}, 3 \% \mathrm{CO}_{2}$ and then transfected with $100 \mathrm{nM}$ of either nonsense non-targeting siRNA or target-specific siRNAs to knockdown OPN for $24 \mathrm{~h}$ and $72 \mathrm{~h}$. The siRNA oligonucleotide sequences are shown in Table 1.

Furthermore, the cells were irradiated in tissue culture flasks (Greiner, Frickenhausen, Germany) at 2, 4 or 6 Gy $24 \mathrm{~h}$ after OPN siRNA transfection. Irradiation at 0 to 6 Gy was accomplished in logarithmically growing cultures with $6 \mathrm{MV}$ photons and adequate bolus material on a SIEMENS ONCOR (Erlangen, Germany) linear accelerator at a dose rate of $2 \mathrm{~Gy} / \mathrm{min}$. Referring to the fractionated daily dose in therapy treatment and $\mathrm{DMF}_{10}$-value of the MDA-MB-231 cell line, we have chosen a radiation dose of 2 Gy and 6 Gy, respectively. At $1 \mathrm{~h}$ and $48 \mathrm{~h}$ after irradiation, cells were processed for RNA and protein extraction, clonogenic assays $(1 \mathrm{~h})$ and migration and apoptosis assays (48 h).

\section{Quantitative real-time RT-PCR (qRT-PCR)}

Total RNA was isolated using the RNeasy ${ }^{\circ}$ Mini Kit as recommended by the manufacturer (Qiagen, Hilden, Germany). For hybridization, $1 \mu \mathrm{g}$ of RNA was incubated with random primers $(150 \mathrm{ng} / \mu \mathrm{L})$ at $70^{\circ} \mathrm{C}$ for $10 \mathrm{~min}$ followed by addition of $5 \times$ first strand buffer, $0.1 \mathrm{M}$ DTT, $2.5 \mathrm{mM}$ dNTPs and SuperScript ${ }^{\mathrm{mt}}$ II reverse transcriptase $(200 \mathrm{U} / \mu \mathrm{l})$ (Invitrogen). The reaction conditions were: $20^{\circ} \mathrm{C}$ for $10 \mathrm{~min}, 42^{\circ} \mathrm{C}$ for $80 \mathrm{~min}$ and $95^{\circ} \mathrm{C}$ for $10 \mathrm{~min}$.

\section{Table 1 siRNAs}

\begin{tabular}{lllll}
\hline target-mRNA & siRNA & sequence ${\text { 5' } \rightarrow \mathbf{3}^{\prime}}^{\prime}$ & localization & source \\
\hline nonsense & Lu GL2 & 5'-CGTACGCGGAATACTTCGA-3' & & \\
osteopontin & Mix (SMART pool) & 5'-CAUCUUCUGAGGUCAAUUA-3' & 1091-2009 & Dharmacon Inc. (Chicago, IL, USA) \\
& & 5'-UGAACGCGCCUUCUGAUUG-3' & $797-814$ & \\
osteopontin & 5'-CCGAUGUGAUUGAUAGUCA-3' & $938-956$ & \\
\hline
\end{tabular}

Sequences and localization of siRNAs used in this study that correspond to mRNA sequences of OPN [GenBank: NM_001040058] 
All qRT-PCR reactions were performed on a Rotorgene RG-6000 (LTF, Wasserburg, Germany) using the QuantiTect SYBRGreen PCR Kit (Qiagen). For each PCR reaction, $1 \mu \mathrm{l}$ of $\mathrm{cDNA}$ was added to SYBRGreen Quantitect $2 \times$, PCR primers $(20 \mu \mathrm{M})$ and aqua bidest in a total volume of $15 \mu \mathrm{l}$. As a negative control, we used a no-template reaction. The primers used are cited in Table 2. HPRT (hypoxanthineguanine phosphoribosyltransferase) served as a housekeeping gene and for control of cDNA integrity. PCR conditions were: $95^{\circ} \mathrm{C}$ for $15 \mathrm{~min}$ followed by 40 cycles of denaturation for $30 \mathrm{~s}$ at $95^{\circ} \mathrm{C}$, hybridization for $30 \mathrm{~s}$ at $60^{\circ} \mathrm{C}$, extension for $30 \mathrm{~s}$ at $72^{\circ} \mathrm{C}$, a final step for $30 \mathrm{~s}$ at $60^{\circ} \mathrm{C}$ and a melting curve program $\left(65-95^{\circ} \mathrm{C}\right.$ with a heating rate of $\left.0.2^{\circ} \mathrm{C} / \mathrm{s}\right)$. RNA was isolated as well as cDNA was generated and quantified from three independent experiments.

\section{Western blot hybridization}

The cells were lysed in RIPA buffer $(50 \mathrm{mM}$ Tris- $\mathrm{HCl}$ pH 7.4, $200 \mathrm{mM} \mathrm{NaCl}, 1 \mathrm{mM}$ EDTA, $1 \mathrm{mM}$ EGTA, 1\% Triton X-100, $0.25 \%$ desoxycholate, 1:100 phosphatase inhibitor, 1:100 proteinase inhibitor) followed by ultrasonic homogenization. The conditioned medium (serumfree RPMI) was harvested after $24 \mathrm{~h}$ and $48 \mathrm{~h}$ and spun at $1,300 \mathrm{rpm}$ for $10 \mathrm{~min}$ to remove cell debris. The supernatant was concentrated using Amicon ${ }^{\circ}$ Ultra Centrifugal Filters (Millipore, Billerica, MA, USA) with a 3 kDa cut-off.

Equal amounts of protein (15-20 $\mu \mathrm{g} / \mathrm{lane})$ were electrophoresed on 4-12\% Bis-Tris gradient gels (Invitrogen) under reducing conditions and transferred to PDVF membrane (Millipore GmbH, Schwalbach, Germany). The membrane was blocked with $10 \%$ non-fat milk in TBST $(50 \mathrm{mM} \mathrm{NaCl}, 30 \mathrm{mM}$ Tris- $\mathrm{HCl} \mathrm{pH} 8.0,0.1 \%$ Tween) for $1 \mathrm{~h}$ and probed with polyclonal rabbit antihuman OPN (1:2,000, 0-17, IBL, Hamburg, Germany), rabbit anti-human cleaved PARP (poly-(ADP-ribose)polymerase) (Asp214) (1:2,000, Cell Signaling, Danvers, MA, USA) and mouse anti- $\beta$-actin (1:5,000, Sigma, Steinheim, Germany) at $4^{\circ} \mathrm{C}$ overnight. The membrane was washed three times with TBST buffer for 7 min followed by incubation with HRP-conjugated secondary antibodies (DAKO, Hamburg, Germany) diluted 1:5,000 in TBST containing 10\% non-fat milk for $1 \mathrm{~h}$ at room temperature. After further washing steps (three times with TBST buffer and one time with TBS), the immunocomplexes were visualized by ECL or ECL Plus Blotting Detection System (Amersham, Freiburg, Germany). We analyzed the conditioned medium of two independent experiments and the protein data of three independent experiments.

\section{Clonogenic survival assay and radiosensitivity}

The cells were trypsinized $1 \mathrm{~h}$ after irradiation, and different numbers of cells (100-10,000), depending on treatment and irradiation dose, were seeded into $25-\mathrm{cm}^{2}$ cell culture flasks. The cells were cultured in RPMI supplemented with $10 \%$ FCS in a humidified atmosphere of $3 \% \mathrm{CO}_{2}$ at $37^{\circ} \mathrm{C}$. The cells were incubated for two weeks and then fixed with paraformaldehyde (Sigma), and colony formation (colonies of $\geq 50$ cells) was visualized by staining with $10 \%$ Giemsa solution (Sigma). The number of colonies was counted to determine the survival fraction (SF), determined as the ratio of number of colonies formed by irradiated cells to the number of colonies formed by non-irradiated cells. The enhancement factor was determined as the ratio of the survival fraction of OPN siRNA-treated cells to nonsense siRNA-treated control cells. The $\mathrm{DMF}_{10}$ is the radiation dose that characterizes an effect at the survival level of $10 \%$ of the colonies. The data represent at least three independent experiments.

\section{Migration assays}

Cell migration was assessed using modified Boyden chambers [19]. Cells $\left(2.0^{*} 10^{4}\right)$ were suspended in $300 \mu \mathrm{l}$ of RPMI without FCS and were added to the upper chamber (membrane filter with $8 \mu \mathrm{m}$ pore size), and the bottom chamber was filled with $1 \mathrm{ml}$ of RPMI supplemented with $20 \%$ FCS as chemoattractant. The assay was incubated at $37^{\circ} \mathrm{C}$ in a humidified atmosphere containing $3 \% \mathrm{CO}_{2}$ for at least $16 \mathrm{~h}$. Non-migrating cells on the upper side of the transwell inserts were removed. The migrated cells on the bottom side of the membrane filter were trypsinized and counted with $\mathrm{CASY}^{\circ} \mathrm{DT}$ (Schärfe System GmbH, Reutlingen, Germany). The data represent at least three independent experiments.

Furthermore, we used a wound scratch assay to determine the migration of MDA-MB-231 cells after transfection with OPN siRNA. Cells were grown in 6-well

Table 2 Primers for quantitative real-time RT-PCR

\begin{tabular}{|c|c|c|c|c|}
\hline gene & primer & sequence $5^{\prime} \rightarrow 3^{\prime}$ & & localization \\
\hline \multirow[t]{2}{*}{ HPRT } & HPRT fW & 5'-TTGCTGACCTGCTGGATTAC-3' & sense & $309-328$ \\
\hline & HPRT rev & 5'-CTTGCGACCTTGACCATCTT-3' & antisense & $551-570$ \\
\hline \multirow[t]{2}{*}{ OPN } & OPN fw & 5'-TGGCCGAGGTGATAGTGTG-3' & sense & $555-573$ \\
\hline & OPN rev & 5'-CGGGGATGGCCTTGTATG-3' & antisense & $686-703$ \\
\hline
\end{tabular}

Primer sequences and the localization of the primer binding side in the corresponding mRNA transcript 
culture plates [19] in RPMI culture medium containing $10 \%$ FCS and cultured to $100 \%$ confluence. A uniform cell-free area was created by scratching a confluent monolayer with a $200 \mu \mathrm{l}$ pipette tip. To determine the migration of MDA-MB-231 cells, the wound closure was observed at different time points. The wound scratch assay was also performed in three independent experiments.

\section{Apoptosis}

For quantitative determination of the rate of apoptosis, we analyzed suspended cells and the corresponding supernatant. The cells were fixed with $80 \%$ ethanol (Merck, Darmstadt, Germany) and centrifuged on microscope slides at $1000 \mathrm{~g}$ for $5 \mathrm{~min}$. After staining with DAPI solution (4,6-diamidino-2-phenylindole dihydrochloride) (Serva, Heidelberg, Germany) and washing with PBS, the cells were covered with ProLong ${ }^{\oplus}$ Gold antifade reagent (Invitrogen). The rate of apoptosis was quantified with a fluorescent microscope at 200× magnification (MC 100 Spot, Zeiss universal microscope, Jena, Germany) by counting 500 cells in separate visual fields (described in [20]). The data represent the results of at least three independent experiments.

\section{Statistical analysis}

The experimental results were checked for normal distribution and therefore analyzed by unpaired Student's $t$-test, where $\mathrm{p}<0.05$ was considered as an indicator of a significant difference between mean values.

\section{Results}

Effects of OPN siRNA constructs on mRNA and protein levels with or without irradiation

At $24 \mathrm{~h}$ and $72 \mathrm{~h}$ after transfection, the OPN mRNA level in cells treated with OPN-specific siRNAs (Mix, OpnS) was approximately $20 \%$ compared to that in cells treated with control siRNA (nonsense siRNA) (Fig. 1A.). We further studied the OPN mRNA level after treatment with OPN-specific siRNAs and additional irradiation. We found that irradiation alone had no effect on OPN mRNA levels. However, after irradiation at $2 \mathrm{~Gy}$ in both Mix and OpnS transfected cells, OPN mRNA levels were found to be reduced to $30 \%$ compared to cells treated with control siRNA (Fig. 1A.). These effects could be seen at $24 \mathrm{~h}$ as well as $72 \mathrm{~h}$ after transfection in combination with irradiation at 2, 4 or 6 Gy (data not shown).

Western blot analysis was used to determine the effects of OPN knockdown on the OPN protein level. Transfection with either Mix or OpnS resulted in a clear decrease in the extracellular OPN protein level (Fig. 1B.). However, a decreased intracellular OPN protein level after siRNA transfection was only partially detectable (Fig. 1C.). Furthermore, our experiments demonstrated that the OPN protein level is reduced in control cells transfected with nonsense siRNA after irradiation at 2 Gy
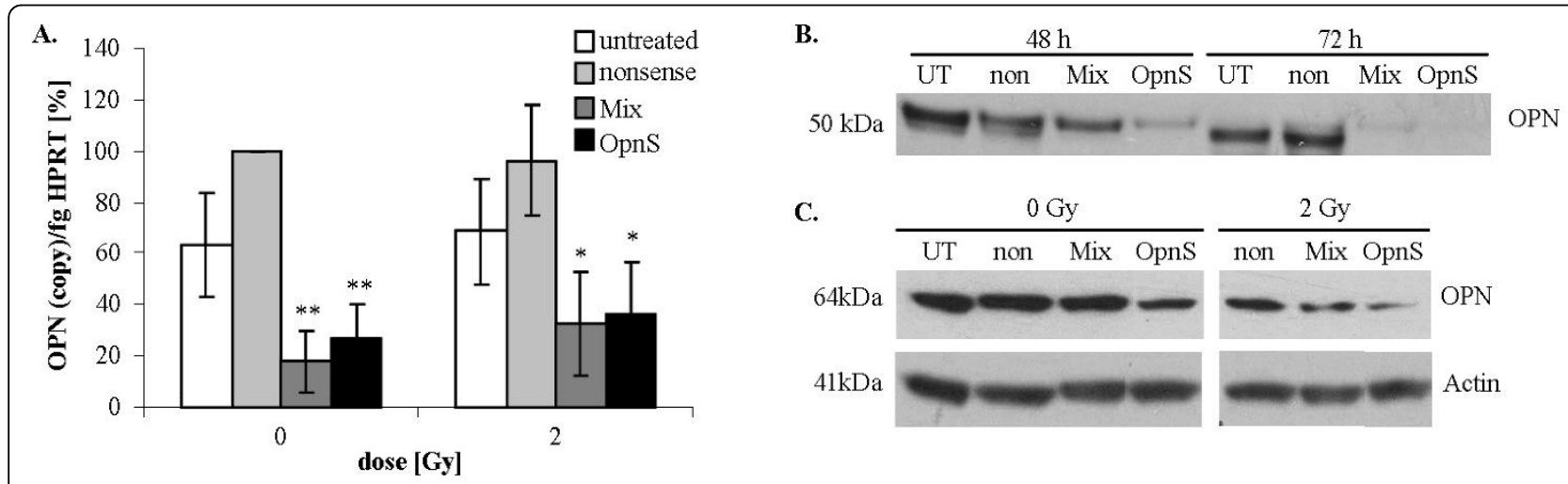

C.
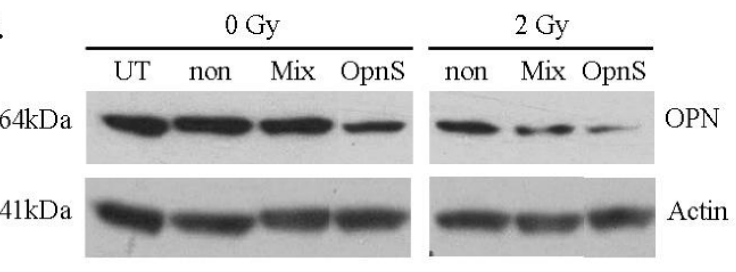

Figure 1 OPN mRNA and protein levels of either non-irradiated or irradiated MDA-MB-231 cells after siRNA transfection. A. Quantitative real-time PCR: OPN mRNA levels of untreated cells and cells treated with siRNA targeting OPN or nonsense siRNA. Representative values of OPN mRNA levels (72 h after transfection) treated with OPN-specific siRNAs were normalized to those treated with nonsense siRNA. The value of the OPN mRNA level of cells that were treated with nonsense siRNA at 0 Gy was arbitrarily established as 100\%. Data represent the average values $( \pm S D)$ of three independent experiments $\left({ }^{*} p<0.05,{ }^{* *} p<0.001\right)$. B./C. Western blot: Western blot analyses of OPN with OPN specific antibody 0-17 (IBL). B. MDA-MB-231 cells were transfected with siRNA Mix as well as OpnS or with nonsense siRNA (non) for $24 \mathrm{~h}$. Thereafter, MDA-MB-231 cells were incubated with serum-free culture media for another $24 \mathrm{~h}$ and $48 \mathrm{~h}$. The Western blot shows the extracellular OPN protein levels $(50 \mathrm{kDa}$ ) of MDA-MB-231 cells $48 \mathrm{~h}$ and $72 \mathrm{~h}$ after transfection with OPN specific siRNA Mix and OpnS, with nonsense siRNA (non) and untreated MDA-MB-231 control cells (UT). The Western blot shows one representative result out of two independent experiments. $\mathbf{C}$. Intracellular OPN protein levels (64 kDa) of MDA-MB-321 cells $24 \mathrm{~h}$ after transfection. Cells were either untreated (UT) or treated with OPN specific siRNA Mix and OpnS or with nonsense siRNA (non) with and without irradiation at 2 Gy. The Western blot shows one representative result out of three independent experiments. Actin served as an internal loading control. 
compared to non-irradiated cells. The irradiationinduced inhibition of OPN protein expression was also detected in cells transfected with OPN siRNAs (Fig.1C.).

\section{Effects of OPN siRNA constructs on migration and} induction of apoptosis with or without irradiation

We determined the effects of OPN siRNA and irradiation on the migration rate of MDA-MB-231 cells with the Boyden chamber assay and scratch assay. Cells transfected with siRNA targeting OPN showed reduced migration rates compared to control cells (control and nonsense siRNA). Transfection with Mix resulted in a decreased migration rate to $40 \%(\mathrm{p}=0.09)$, whereas the migration rate of cells transfected with OpnS was less than $62 \%(p=0.15)$ compared to the migration rate of cells treated with control siRNA (Fig. 2B.). Similarly, we found a reduced migration rate after transfection with OPN siRNA using the scratch assay (Fig. 2A.). Furthermore, we demonstrated that irradiation at 2 Gy to 6 Gy had no effect on the migration rate (data not shown). However, combination of OPN siRNA transfection and irradiation at 2 Gy resulted in a significant inhibition of migration. After incubation with Mix and 2 Gy irradiation, migration was reduced to $32 \%(\mathrm{p}=0.03)$. Additionally, transfection with OpnS and irradiation at 2 Gy attenuated the migration rate to $40 \%(\mathrm{p}=0.03)$. Using Western blot analysis, we examined PARP cleavage as an indicator for the induction of apoptosis. However, 24 h after incubation with OPN siRNA, we could not detect any PARP cleavage products using Mix or OpnS. Moreover, Fig. 3A. shows a distinctive accumulation of the PARP cleavage product $(89 \mathrm{kDa}) 72 \mathrm{~h}$ after transfection with siRNA OpnS. However, only OpnS, not Mix, induced apoptosis (Fig. 3A. and 3B.). In addition, we examined the morphology of the cell nuclei to quantify the rate of apoptosis by the use of DAPI staining. The results observed in Western blot analyses were supported by the findings of the quantitative assay. After incubation with OpnS, the apoptosis rate increased from $0.3 \%$ to
A.

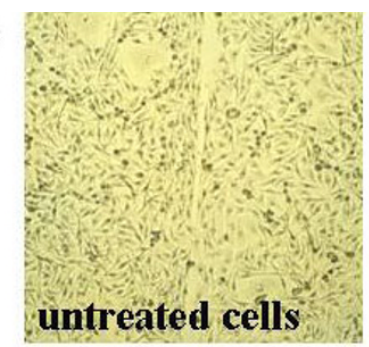

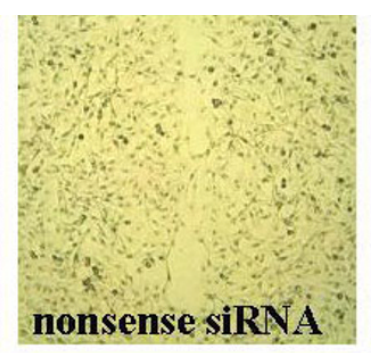
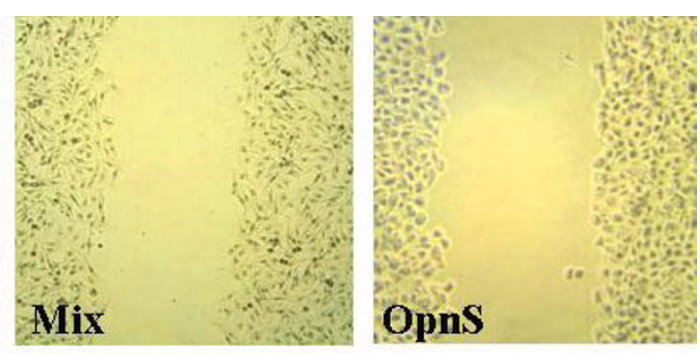

B.

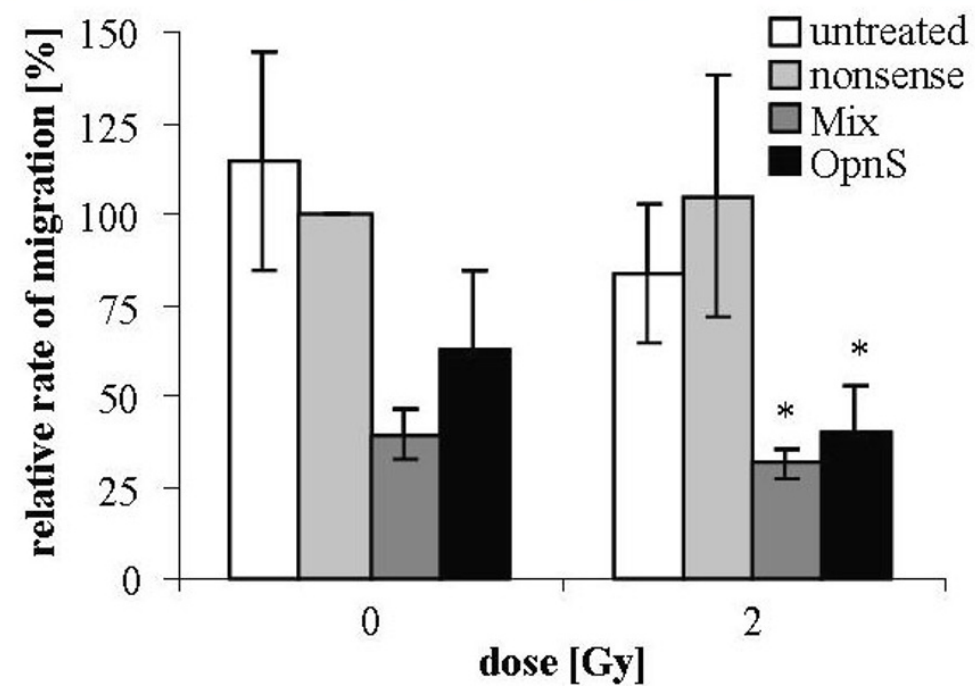

Figure 2 Migration behavior of either non-irradiated or irradiated (2 Gy) MDA-MB-231 cells after siRNA transfection. A. Scratch assay Wound scratch assay of MDA-MB-231 cells $24 \mathrm{~h}$ after transfection. Untreated cells and cells that were treated with nonsense siRNA were able to close the wound scratch by migration. Cells treated with Mix as well as OpnS did not migrate and were unable to close the wound scratch. B. Boyden chamber assay: The migration rate of cells treated with OPN-specific siRNAs was normalized to migration rate of cells treated with nonsense siRNA. Treatment with siRNAs targeting OPN reduced the migration rate in non-irradiated cells as well as in cells irradiated at 2 Gy. The migration rate of cells transfected with nonsense siRNA at 0 Gy was arbitrarily established as $100 \%$. Data represent the average values ( \pm SD) of three independent experiments $(* p<0.05)$. 


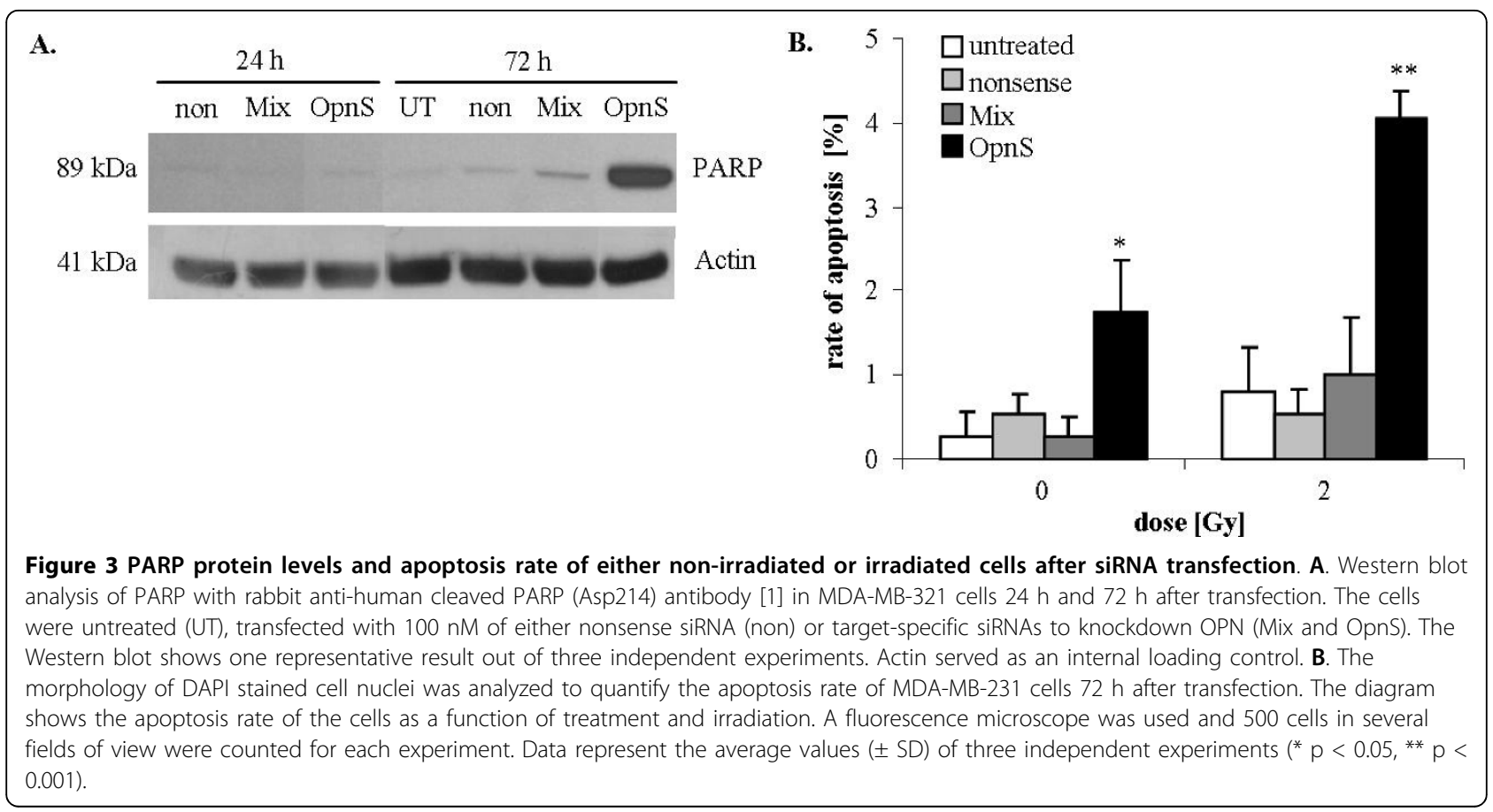

$1.7 \%(\mathrm{p}=0.04)$, whereas transfection with Mix had no effect on apoptosis. We found that irradiation alone at 2 Gy did not significantly increase apoptosis in MDAMB-231 cells (Fig. 3B.). Nevertheless, the combination of OpnS and irradiation at 2 Gy resulted in a significant increase in apoptosis rate to $4 \%(\mathrm{p}=0.0001)$. In contrast to that, incubation with Mix and irradiation at 2 Gy had no effect on apoptosis.

\section{Effects of OPN siRNA on clonogenic survival and radiosensitivity}

We demonstrated that incubation with siRNA OpnS is more effective to reduce the clonogenic survival of MDA-MB-231 cells than incubation with siRNA Mix. In particular, we found that transfection with OpnS significantly decreased the clonogenic survival to $42 \%$ $(\mathrm{p}=0.008)$ (Fig. 4A.). In contrast, transfection with Mix was ineffective at reducing the clonogenic survival $(82 \%)(\mathrm{p}=0.4)$.

Irradiation of MDA-MB-231 cells at 2 Gy reduced the clonogenic survival to $60 \%\left(\mathrm{SF}_{2}=0.60\right)$ (data not shown). The combination of treatment with OpnS siRNA and irradiation also reduced the clonogenic survival as compared to single siRNA treatment. Incubation with OpnS, and additional irradiation at 2 Gy significantly decreased the clonogenic survival to $30 \%$ ( $\mathrm{p}<$ 0.001 ). Furthermore, with higher irradiation dose transfection with OpnS resulted in a weak radiosensitization with a $\mathrm{DMF}_{10}$ of 1.1 and an enhancement factor of 1.5 at $6 \mathrm{~Gy}(\mathrm{p}=0.09)$ (Fig. 4B.).

\section{Discussion}

It is well known that intratumoral and plasma levels of the phosphoprotein OPN are increased in many tumors such as lung cancer [21], esophageal cancer [22], prostate cancer [23], glioma [24], soft tissue sarcoma [25] and breast cancer $[5,14]$. Furthermore, it has been shown that an elevated OPN level is associated with poor prognosis for cancer patients $[5,6,12,14,15]$. In addition, different studies have found that high OPN levels are associated with poor response to conventional treatment modalities including radiotherapy (reviewed in [9]). However, little is known about the relationship between OPN expression and radiosensitivity.

Our analyses demonstrate that both Mix and OpnS siRNAs (Table 1) are suitable to clearly reduce mRNA levels of OPN (Fig. 1A.). Furthermore, we detected a clear decrease of extracellular OPN protein levels after transfection with OPN siRNA (Fig. 1B.). In contrast, the intracellular OPN protein level was only partially decreased after transfection with OPN siRNA. However, intracellular OPN was detected at a higher molecular weight range $(64 \mathrm{kDa})$ as compared with extracellular OPN that was detected at $50 \mathrm{kDa}$. The molecular weight difference may represent post-translational modifications such as glycosylation, phosphorylation and sulfatization $[4,26,27]$. In addition, there is evidence from the literature that two forms of OPN exist: a secreted form $(\mathrm{sOPN})$ and an intracellular form (iOPN). Shinohara and co-workers [28] proposed that sOPN and iOPN represent alternative translational products of a single 


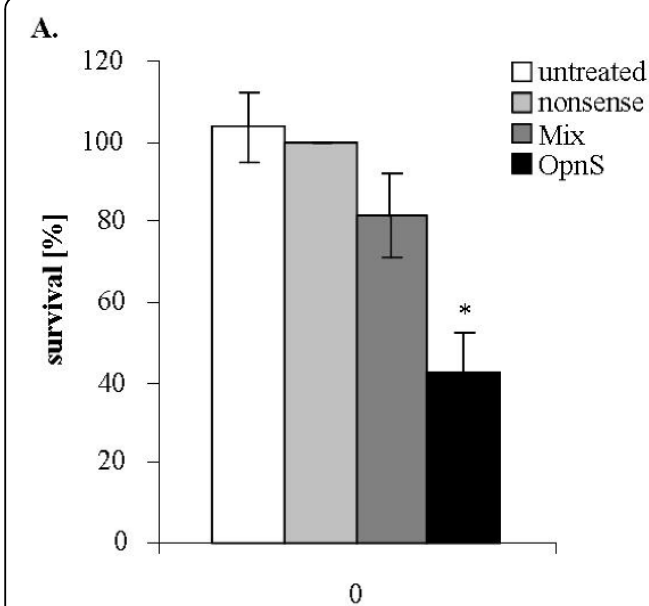

dose $[\mathrm{Gy}]$
B.

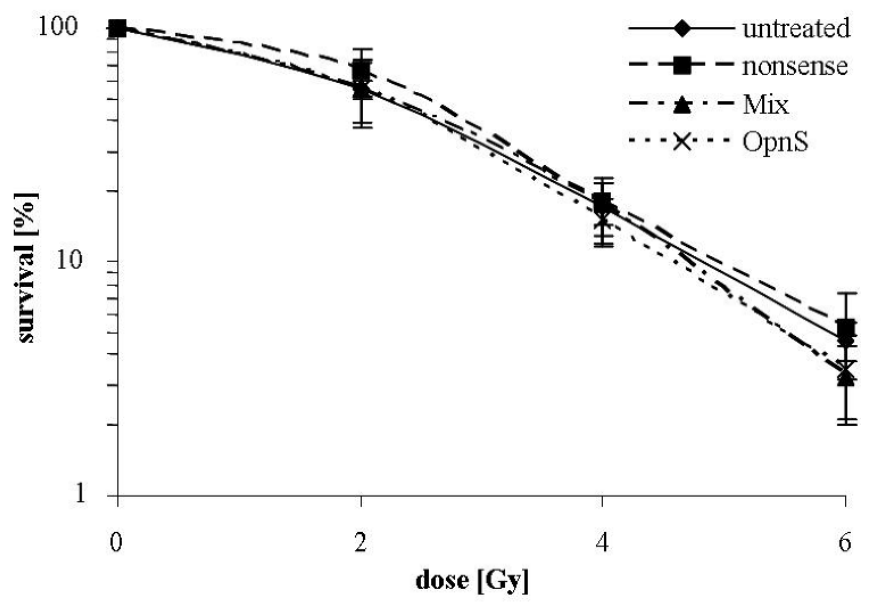

Figure 4 Clonogenic survival of either non-irradiated or irradiated MDA-MB-231 cells after siRNA transfection. A. Clonogenic survival of MDA-MB-231 cells after transfection. Treatment with just OpnS had a strong effect on clonogenic survival at 0 Gy. The relative clonogenic survival of cells that were transfected with nonsense siRNA was arbitrarily established as 100\%. Data represent the average values ( \pm SD) of three independent experiments $\left({ }^{*} p<0.05,{ }^{* *} p<0.001\right)$. B. Clonogenic survival after transfection with OPN-specific siRNA (Mix, OpnS) in combination with irradiation at 2, 4 or $6 \mathrm{~Gy}$. To examine the additional effects of irradiation all values of clonogenic survival at 0 Gy were set arbitrarily at 100\%. Cells transfected with OpnS showed an increased radiosensitivity. After irradiation at 6 Gy, a dose modifying factor (DMF $\left.F_{10}\right)$ of 1.1 and an enhancement factor of $1.5(p=0.09)$ were calculated for the siRNA construct OpnS. Data represent the average values $( \pm$ SD) of three independent experiments.

full-length OPN mRNA that have a molecular weight difference of $5 \mathrm{kDa}$. In contrast to sOPN, the iOPN protein lacks a signal peptide, which allows the iOPN protein to localize to the cytoplasm but not to the Golgi apparatus [28]. Furthermore, it has been shown that extracellular OPN is important for bone marrow cell activation and the subsequent outgrowth of distant tumors [19], and it also affects the cellular response and increases lung metastasis in mice that have received cells preincubated with OPN [29].

The siRNA transfection showed clear effects on different cellular parameters. Treatment with OpnS resulted in a clear reduction of clonogenic survival, inhibition of migration and increased rate of apoptosis (Fig. 2, 3, 4A.), whereas treatment with the siRNA construct Mix caused an obvious reduction in the rate of migration. However, no differential effects were found with respect to apoptosis and clonogenic survival. The different effects of OpnS and Mix on clonogenic survival and apoptosis frequency are possibly caused by the different sequences that are recognized by the siRNAs. Possibly, OPN RNA sequences are not assessable in the same way by the different siRNAs. Mix is a pool of four siRNAs and might cause more off-target effects than OpnS which could reverse the original effects. We chose the siRNA technology for transient inhibition of OPN expression in MDA-MB-231 cells. A disadvantage of the siRNA technology is that it is not possible to reach a permanent reduction of OPN expression. However, in vitro it is an efficient method to knockdown OPN.

Taken together the effects of OPN inhibition are in agreement with previous findings that the knockdown of OPN reduces the clonogenic survival, migration and invasion rate, and proliferation in different breast cancer cell lines [30-32]. Furthermore, various studies have demonstrated the effects of OPN silencing or OPN overexpression on several downstream elements of OPN in Western blot analysis. In particular, Tuck and coworkers [33,34] found an induction of uPA expression in response to OPN treatment and an association of uPA expression with OPN-induced invasion and migration in human breast cancer cells. These findings are consistent with our data analyzing the protein expression levels of the migration marker uPA with ELISA in cell lysates of MDA-MB-231 cells that showed a clear, albeit not significant, reduction of uPA protein levels after transfection with OPN siRNAs and irradiation (data not shown). Other investigators have demonstrated that knockdown of OPN decreases the expression of PI3'-kinase, JNK1/2, Src and Akt, uPA, MMP-2 and -9 in various tumor cell lines [35-39].

In the present study, for the first time we were able to demonstrate that OPN silencing affects the radiobiological behavior of human cancer cells. Moreover, we found that OPN knockdown by OPN siRNA could very effectively decrease OPN mRNA and protein levels after additional irradiation (Fig. 1). Furthermore, an additional 
decrease in the intracellular OPN protein level was detected in Western blot analyses after irradiation (Fig. 1C.). However, another study analyzed the effect of radiation on OPN levels in osteoblastic cells and found a slightly elevated expression of OPN on days 14 and 21 after irradiation [40].

Moreover, the additional irradiation at 2 Gy caused a significant reduction in the rate of migration (Fig. 2B.). We demonstrated that treatment with OpnS resulted in a significant increase in irradiation-induced apoptosis (Fig. 3B.). This is in agreement with Lee and co-workers [41], who showed that treatment with recombinant OPN confers an increased resistance to UV-induced apoptosis in HT29 cells [41]. However, OPN siRNA transfection alone and in combination with irradiation showed only minor effects on apoptosis compared with effects on clonogenic survival. Possibly the MAA (methoxyacetic acid) assay can reflect a better correlation because besides apoptosis this assay determines other modes of cell death such as micronucleation or multinucleated cells [42].

To our knowledge, this is the first study demonstrating that knockdown of OPN influences the radiosensitivity of cancer cells. OPN knockdown even caused a weak radiosensitization with a higher irradiation dose (Fig. 4B.). Considering the non-significant effects on radiosensitivity in vitro it appears that OPN siRNA treatment predominantly affects clonogenicity and migration rate. However, in vivo we cannot be sure that siRNAs would find their target molecules and concentrate as it would be appropriate in solid tumors. Therefore, a combined treatment of siRNAs with irradiation might be necessary. Another study which analyzed the influence of OPN silencing confirmed the impact of OPN expression on the efficacy of irradiation. Solberg and co-workers [43] found that irradiation of xenograft tumors in mice induces the expression of mouse VEGF (mVEGF) and mouse OPN (mOPN), which are both closely associated with angiogenesis. Moreover, the expression of mOPN was directly proportional to the mVEGF levels in tumors which indicates that mOPN can serve as an alternative marker of tumor recovery after radiotherapy. Furthermore, clinical studies have found that elevated OPN levels are associated with poor prognosis in head and neck cancer $[9,12,13,44-47]$ and breast cancer $[3,48]$.

\section{Conclusions}

In summary, in the present study we were able to demonstrate for the first time that an OPN knockdown combined with irradiation has additive effects on clonogenic survival, migration and the induction of apoptosis. Furthermore, we showed that silencing of OPN with siRNA causes a weak radiosensitization of MDA-MB-
231 cells. This suggests that OPN is an attractive target to improve the efficacy of radiotherapy. Additional radiobiological studies are necessary to investigate the role of OPN and its association with radiosensitivity of other tumor cell lines.

\section{Acknowledgements}

We would like to thank our colleagues from the Department of Radiotherapy for contributing to this study and for their continuous support. We would also like to thank Kathrin Spröte, Gabriele Thomas and Antje Zobjack for their excellent technical assistance. This work was supported by the Wilhelm Sander Stiftung (grant number: 2007.123.1).

\section{Author details}

'Department of Radiotherapy, Martin-Luther-University Halle-Wittenberg, Dryanderstr.4, 06110 Halle, Germany. ${ }^{2}$ Department of Oral and Maxillofacial Plastic Surgery, Martin-Luther-University Halle-Wittenberg, Ernst-Grube-Str.40, 06120 Halle, Germany. ${ }^{3}$ Institute of Pathology, Dresden University of Technology, Fetscherstr.74, 01307 Dresden, Germany.

\section{Authors' contributions}

$\mathrm{AH}$ designed the study, performed experimental procedures, analyzed the data and drafted the manuscript. HW, MKa, HT and DV aided in study design, analyzed the data and reviewed the manuscript. MKo performed experimental procedures, analyzed the data and reviewed the manuscript. MB designed the study, analyzed the data and drafted the manuscript. All authors read and approved the final manuscript.

\section{Competing interests}

The authors declare that they have no competing interests.

Received: 6 July 2010 Accepted: 17 September 2010

Published: 17 September 2010

\section{References}

1. Rangaswami $H$, Bulbule A, Kundu GC: Osteopontin: role in cell signaling and cancer progression. Trends Cell Biol 2006, 16:79-87.

2. Wai PY, Kuo PC: Osteopontin: regulation in tumor metastasis. Cancer Metastasis Rev 2008, 27:103-118.

3. Bramwell VH, Doig GS, Tuck AB, Wilson SM, Tonkin KS, Tomiak A, Perera F, Vandenberg TA, Chambers AF: Serial plasma osteopontin levels have prognostic value in metastatic breast cancer. Clin Cancer Res 2006 12:3337-3343.

4. Kazanecki CC, Kowalski AJ, Ding T, Rittling SR, Denhardt DT: Characterization of anti-osteopontin monoclonal antibodies: Binding sensitivity to post-translational modifications. J Cell Biochem 2007, 102:925-935

5. Singhal $H$, Bautista DS, Tonkin KS, O'Malley FP, Tuck AB, Chambers AF, Harris JF: Elevated plasma osteopontin in metastatic breast cancer associated with increased tumor burden and decreased survival. Clin Cancer Res 1997, 3:605-611.

6. Wu CY, Wu MS, Chiang EP, Wu CC, Chen YJ, Chen CJ, Chi NH, Chen GH, Lin JT: Elevated plasma osteopontin associated with gastric cancer development, invasion and survival. Gut 2007, 56:782-789.

7. Vergis R, Corbishley CM, Norman AR, Bartlett J, Jhavar S, Borre M, Heeboll S, Horwich A, Huddart R, Khoo V, Eeles R, Cooper C, Sydes M, Dearnaley D, Parker C: Intrinsic markers of tumour hypoxia and angiogenesis in localised prostate cancer and outcome of radical treatment: a retrospective analysis of two randomised radiotherapy trials and one surgical cohort study. Lancet Oncol 2008, 9:342-351.

8. Debucquoy A, Goethals L, Geboes K, Roels S, Mc Bride WH, Haustermans K: Molecular responses of rectal cancer to preoperative chemoradiation. Radiother Oncol 2006, 80:172-177.

9. Bache M, Kappler M, Said HM, Staab A, Vordermark D: Detection and specific targeting of hypoxic regions within solid tumors: current preclinical and clinical strategies. Curr Med Chem 2008, 15:322-338.

10. Vordermark D, Said HM, Katzer A, Kuhnt T, Hansgen G, Dunst J, Flentje M, Bache M: Plasma osteopontin levels in patients with head and neck 
cancer and cervix cancer are critically dependent on the choice of ELISA system. BMC Cancer 2006, 6:207.

11. Bache M, Reddemann R, Said HM, Holzhausen HJ, Taubert H, Becker A, Kuhnt T, Hansgen G, Dunst J, Vordermark D: Immunohistochemical detection of osteopontin in advanced head-and-neck cancer: prognostic role and correlation with oxygen electrode measurements, hypoxiainducible-factor-1alpha-related markers, and hemoglobin levels. Int $\mathrm{J}$ Radiat Oncol Biol Phys 2006, 66:1481-1487.

12. Le QT, Sutphin PD, Raychaudhuri S, Yu SC, Terris DJ, Lin HS, Lum B, Pinto HA, Koong AC, Giaccia AJ: Identification of osteopontin as a prognostic plasma marker for head and neck squamous cell carcinomas. Clin Cancer Res 2003, 9:59-67.

13. Overgaard J, Eriksen JG, Nordsmark M, Alsner J, Horsman MR: Plasma osteopontin, hypoxia, and response to the hypoxia sensitiser nimorazole in radiotherapy of head and neck cancer: results from the DAHANCA 5 randomised double-blind placebo-controlled trial. Lancet Oncol 2005, 6:757-764.

14. Tuck AB, O'Malley FP, Singhal H, Harris JF, Tonkin KS, Kerkvliet N, Saad Z, Doig GS, Chambers AF: Osteopontin expression in a group of lymph node negative breast cancer patients. Int J Cancer 1998, 79:502-508.

15. Rudland PS, Platt-Higgins A, El Tanani M, De Silva RS, Barraclough R, Winstanley JH, Howitt R, West CR: Prognostic significance of the metastasis-associated protein osteopontin in human breast cancer. Cancer Res 2002, 62:3417-3427.

16. Siles E, Villalobos M, Valenzuela MT, Nunez Ml, Gordon A, McMillan TJ, Pedraza V, Ruiz de Almodovar JM: Relationship between p53 status and radiosensitivity in human tumour cell lines. Br J Cancer 1996, 73:581-588.

17. Torres-Roca JF, Eschrich S, Zhao H, Bloom G, Sung J, McCarthy S, Cantor AB, Scuto A, Li C, Zhang S, Jove R, Yeatman T: Prediction of radiation sensitivity using a gene expression classifier. Cancer Res 2005, 65:7169-7176

18. Phillips TM, McBride WH, Pajonk F: The response of CD24(-/low)/CD44+ breast cancer-initiating cells to radiation. J Nat/ Cancer Inst 2006, 98:1777-1785.

19. McAllister SS, Gifford AM, Greiner AL, Kelleher SP, Saelzler MP, Ince TA, Reinhardt F, Harris LN, Hylander BL, Repasky EA, Weinberg RA: Systemic endocrine instigation of indolent tumor growth requires osteopontin. Cell 2008, 133:994-1005.

20. Bache $M$, Würl P, Dietzel M, Meye A, Fröde $D$, Schmidt $H$, Rath FW, Wohlrab W, Dralle H, Dunst J, Taubert H: Two human sarcoma cell lines with different p53 gene status in their response on radiation. Int J Oncol 1997, 11:993-997.

21. Chambers AF, Wilson SM, Kerkvliet N, O'Malley FP, Harris JF, Casson AG: Osteopontin expression in lung cancer. Lung Cancer 1996, 15:311-323.

22. Casson AG, Wilson SM, McCart JA, O'Malley FP, Ozcelik H, Tsao MS, Chambers AF: ras mutation and expression of the ras-regulated genes osteopontin and cathepsin L in human esophageal cancer. Int J Cancer 1997, 72:739-745.

23. Thalmann GN, Sikes RA, Devoll RE, Kiefer JA, Markwalder R, Klima I, FarachCarson CM, Studer UE, Chung LW: Osteopontin: possible role in prostate cancer progression. Clin Cancer Res 1999, 5:2271-2277.

24. Saitoh Y, Kuratsu J, Takeshima H, Yamamoto S, Ushio Y: Expression of osteopontin in human glioma. Its correlation with the malignancy. Lab Invest 1995, 72:55-63.

25. Bache M, Kappler M, Wichmann H, Rot S, Hahnel A, Greither T, Said HM, Kotzsch M, Wurl P, Taubert H, Vordermark D: Elevated tumor and serum levels of the hypoxia-associated protein osteopontin are associated with prognosis for soft tissue sarcoma patients. BMC Cancer 2010, 10:132.

26. Christensen B, Nielsen MS, Haselmann KF, Petersen TE, Sorensen ES: Posttranslationally modified residues of native human osteopontin are located in clusters: identification of 36 phosphorylation and five $\mathrm{O}$ glycosylation sites and their biological implications. Biochem J 2005, 390:285-292.

27. Sorensen ES, Hojrup P, Petersen TE: Posttranslational modifications of bovine osteopontin: identification of twenty-eight phosphorylation and three O-glycosylation sites. Protein Sci 1995, 4:2040-2049.

28. Shinohara ML, Kim HJ, Kim JH, Garcia VA, Cantor H: Alternative translation of osteopontin generates intracellular and secreted isoforms that mediate distinct biological activities in dendritic cells. Proc Natl Acad Sci USA 2008, 105:7235-7239.
29. Mandelin J, Lin EC, Hu DD, Knowles SK, Do KA, Wang X, Sage EH, Smith JW, Arap W, Pasqualini R: Extracellular and intracellular mechanisms that mediate the metastatic activity of exogenous osteopontin. Cancer 2009, 115:1753-1764.

30. Adwan H, Bauerle T, Najajreh Y, Elazer V, Golomb G, Berger MR: Decreased levels of osteopontin and bone sialoprotein II are correlated with reduced proliferation, colony formation, and migration of GFP-MDA-MB231 cells. Int J Oncol 2004, 24:1235-1244.

31. Chakraborty G, Jain S, Patil TV, Kundu GC: Down-regulation of osteopontin attenuates breast tumour progression in vivo. J Cell Mol Med 2008, 12:2305-2318.

32. Shevde LA, Samant RS, Paik JC, Metge BJ, Chambers AF, Casey G, Frost AR, Welch DR: Osteopontin knockdown suppresses tumorigenicity of human metastatic breast carcinoma, MDA-MB-435. Clin Exp Metastasis 2006, 23:123-133.

33. Tuck AB, Arsenault DM, O'Malley FP, Hota C, Ling MC, Wilson SM, Chambers AF: Osteopontin induces increased invasiveness and plasminogen activator expression of human mammary epithelial cells. Oncogene 1999, 18:4237-4246.

34. Tuck AB, Hota C, Chambers AF: Osteopontin(OPN)-induced increase in human mammary epithelial cell invasiveness is urokinase (UPA)dependent. Breast Cancer Res Treat 2001, 70:197-204.

35. Chakraborty G, Jain S, Kundu GC: Osteopontin promotes vascular endothelial growth factor-dependent breast tumor growth and angiogenesis via autocrine and paracrine mechanisms. Cancer Res 2008, 68:152-161.

36. Cheng J, Huo DH, Kuang DM, Yang J, Zheng L, Zhuang SM: Human macrophages promote the motility and invasiveness of osteopontinknockdown tumor cells. Cancer Res 2007, 67:5141-5147.

37. Desai B, Rogers MJ, Chellaiah MA: Mechanisms of osteopontin and CD44 as metastatic principles in prostate cancer cells. Mol Cancer 2007, 6:18

38. Ito T, Hashimoto Y, Tanaka E, Kan T, Tsunoda S, Sato F, Higashiyama M, Okumura T, Shimada Y: An inducible short-hairpin RNA vector against osteopontin reduces metastatic potential of human esophageal squamous cell carcinoma in vitro and in vivo. Clin Cancer Res 2006, 12:1308-1316.

39. Mi Z, Guo H, Russell MB, Liu Y, Sullenger BA, Kuo PC: RNA aptamer blockade of osteopontin inhibits growth and metastasis of MDA-MB231 breast cancer cells. Mol Ther 2009, 17:153-161.

40. Gevorgyan A, Sukhu B, Alman BA, Bristow RG, Pang CY, Forrest CR: Radiation effects and radioprotection in MC3T3-E1 mouse calvarial osteoblastic cells. Plast Reconstr Surg 2008, 122:1025-1035.

41. Lee JL, Wang MJ, Sudhir PR, Chen GD, Chi CW, Chen JY: Osteopontin promotes integrin activation through outside-in and inside-out mechanisms: OPN-CD44V interaction enhances survival in gastrointestinal cancer cells. Cancer Res 2007, 67:2089-2097.

42. Abend M, Kehe K, Kehe K, Riedel M, Van Beuningen D: Correlation of micronucleus and apoptosis assays with reproductive cell death can be improved by considering other modes of death. Int I Radiat Biol 2000, 76:249-259.

43. Solberg TD, Nearman J, Mullins J, Li S, Baranowska-Kortylewicz J: Correlation between tumor growth delay and expression of cancer and host VEGF, VEGFR2, and osteopontin in response to radiotherapy. Int J Radiat Oncol Biol Phys 2008, 72:918-926.

44. Celetti A, Testa D, Staibano S, Merolla F, Guarino V, Castellone MD, lovine R, Mansueto G, Somma P, De Rosa G, Galli V, Melillo RM, Santoro M: Overexpression of the cytokine osteopontin identifies aggressive laryngeal squamous cell carcinomas and enhances carcinoma cell proliferation and invasiveness. Clin Cancer Res 2005, 11:8019-8027.

45. Hui EP, Sung FL, Yu BK, Wong CS, Ma BB, Lin X, Chan A, Wong WL, Chan AT: Plasma osteopontin, hypoxia, and response to radiotherapy in nasopharyngeal cancer. Clin Cancer Res 2008, 14:7080-7087.

46. Nordsmark M, Eriksen JG, Gebski V, Alsner J, Horsman MR, Overgaard J: Differential risk assessments from five hypoxia specific assays: The basis for biologically adapted individualized radiotherapy in advanced head and neck cancer patients. Radiother Oncol 2007, 83:389-397.

47. Petrik D, Lavori PW, Cao H, Zhu Y, Wong P, Christofferson E, Kaplan MJ, Pinto HA, Sutphin P, Koong AC, Giaccia AJ, Le QT: Plasma osteopontin is an independent prognostic marker for head and neck cancers. J Clin Oncol 2006, 24:5291-5297. 
48. De Silva RS, Martin L, Roshanlall C, Winstanley J, Leinster S, Platt-Higgins A, Carroll J, West C, Barraclough R, Rudland P: Association of S100A4 and osteopontin with specific prognostic factors and survival of patients with minimally invasive breast cancer. Clin Cancer Res 2006, 12:1192-1200.

doi:10.1186/1748-717X-5-82

Cite this article as: Hahnel et al.: Effects of osteopontin inhibition on radiosensitivityof MDA-MB-231 breast cancer cells. Radiation Oncology 2010 5:82.

Submit your next manuscript to BioMed Central and take full advantage of:

- Convenient online submission

- Thorough peer review

- No space constraints or color figure charges

- Immediate publication on acceptance

- Inclusion in PubMed, CAS, Scopus and Google Scholar

- Research which is freely available for redistribution

Submit your manuscript at www.biomedcentral.com/submit 